\title{
Correction to: Effects of Homogenization Treatment on the Microsegregation of a Ni-Co Based Superalloy Produced by Directional Solidification
}

\author{
Zijian Zhou $^{1,2} \cdot$ Rui Zhang $^{1} \cdot$ Chuanyong Cui ${ }^{1} \cdot$ Yizhou Zhou $^{1} \cdot$ Xiaofeng Sun $^{1}$ \\ Published online: 19 July 2021 \\ (c) The Chinese Society for Metals (CSM) and Springer-Verlag GmbH Germany, part of Springer Nature 2021
}

\section{Correction to: \\ Acta Metallurgica Sinica (English Letters) \\ (2021) 34:943-954 \\ https://doi.org/10.1007/s40195-021-01192-7}

In the Original publication of the article, the Chinese title and author names appeared inadvertently in the Ref. [24]. The corrected Ref. [24] is given below:
B. Ma, S.Y. Ren, X.H. Jiang, Phys. Exam. Test. 4, 6 (1994). (in Chinese). https://doi.org/10.13228/j.boyuan. issn1001-0777.1994.04.002.

Available online at http://link.springer.com/journal/40195.

The original article can be found online at https://doi.org/10.1007/ s40195-021-01192-7.

\section{Rui Zhang}

rzhang@imr.ac.cn

$\triangle$ Chuanyong Cui chycui@imr.ac.cn

1 Shi-Changxu Innovation Center for Advanced Materials, Institute of Metal Research, Chinese Academy of Sciences, Shenyang 110016, China

2 School of Materials Science and Engineering, University of Science and Technology of China, Shenyang 110016, China 